\title{
Single-stage AC/DC Dual Inductor BCM Current-Fed Push-Pull for HB-LED lighting applications
}

\author{
Ignacio Castro, Kevin Martin, Diego G. Lamar, Manuel Arias, Marta M. Hernando and Javier Sebastian \\ Departamento de Ingeniería Eléctrica, Electrónica, de Computadores y Sistemas \\ University of Oviedo \\ Gijón 33204, Spain \\ e-mail: castroignacio@uniovi.es
}

\begin{abstract}
A single-stage, AC/DC driver for High Brightness Light-Emitting Diodes (HB-LED) with galvanic isolation is presented in this paper. The driver is based on a Dual Inductor Current-fed Push-Pull (DICPP) converter with each inductor operating in Boundary Conduction Mode (BCM). The interleaving between the two inductors makes possible for the converter to reduce the high input current ripple of a BCM. Moreover, it is fully compliant with IEC 1000-3-2 Class $\mathrm{C}$, and it is also able to achieve high Power Factor (PF). Moreover, the low component count, simplicity and overall outstanding characteristics make this topology suitable for medium power range HB-LED drivers in low cost applications.

Finally, the proposed topology has been tested on a $90 \mathrm{~W}$ prototype for the full range of the US single-phase line voltage, feeding several strings of HB-LED, with an output voltage of $48 \mathrm{~V}$ at full load. The prototype achieves a maximum efficiency of $92 \%$ with 0.99 power factor, $8 \%$ THD at full load and guarantees good quality light.
\end{abstract}

Keywords-Single phase, Ac-dc power conversion, Power Factor Correction, HB-LED driver

\section{INTRODUCTION}

High-Brightness Light-Emitting Diodes (HB-LED) are increasingly becoming the main source of artificial light in our homes, offices and streets due to their reliability, long life, energy efficiency and low maintenance requirements. However, the driving of HB-LED with primary access to single phase AC requires the use of a converter that achieves high efficiency, Power Factor Correction (PFC) in order to comply with the regulation for both residential and commercial lighting and a long lifespan comparable to that of the HB-LEDs. High Power Factor $(\mathrm{PF})$ is required to maximize the power transferred by the grid. Energy Star ${ }^{\circledR}$ [1], requires $0.7 \mathrm{PF}$ for residential lighting and $0.9 \mathrm{PF}$ for commercial lighting. Furthermore, the lowfrequency harmonic content of the line current, must comply with IEC 1000-3-2 Class C [2]-[4], which establishes very strict harmonic content for the line current, for lighting equipment of more than $25 \mathrm{~W}$. Therefore, the line current needs to have a sinusoidal shape following that of the input voltage. Traditionally, HB-LED drivers are based on a high-performance AC/DC PFC converter, followed by a dc-dc converter (in most situations with galvanic isolation), that provides constant current to the HB-LED, in order to comply with the aforementioned regulation.

Nonetheless, in most scenarios, the cost of the HB-LED driver is the main concern and a single-stage has to be used,

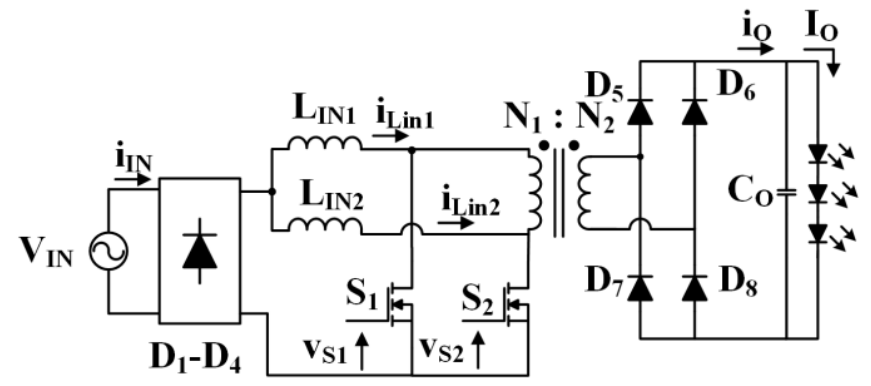

Fig. 1. Proposed single-stage HB-LED driver, DICPP.

especially in medium power range HB-LED drivers, where galvanic isolation is recommended for safety requirements. For that reason, isolated buck-boost topologies, like the flyback working in Discontinuous Conduction Mode (DCM), which achieve unity PF naturally are widely used [5]-[7]. Although, these topologies have a low component count, they suffer from having low efficiencies $(<90 \%)$ and the inability to remove the bulk capacitor needed in PFC. Nevertheless, the removal of the bulk capacitor is not always possible in a single-stage without including more active components [8]-[11] or distorting the input current [12] [13] due to the pulsating input power of the grid.

Another topology that is able to achieve unity PF naturally, by means of control, is the boost converter. The boost converter is normally used as a front-end AC/DC PFC converter operating either in Boundary Conduction Mode (BCM) or with a Multiplier-Based Control (MBC) [14] [15] with a cascaded stepdown converter normally with galvanic isolation. The isolated variations of the boost family converters are suitable to be used in a single-stage PFC. It should be noted that current-fed based isolated converters have some issues, such as, having a complex transformer design or having the need of a demagnetizing path for the main inductance, as has been stated in previous literature [16].

Nevertheless, in previous literature, there have been some works dedicated to single-stage AC/DC PFC current-fed based isolated converters, such as the push-pull [17] or the full-bridge [18]. These topologies are based in the boost converter, hence they can achieve unity PF by working in BCM. However, BCM has an important drawback regarding the size increase of the EMI filter due to the high input current ripple and the variable frequency, which can be reduced by interleaving two or more boost converters in parallel [19]. Therefore, the interleaving of two isolated boosts can reduce the input current ripple of the

This work has been supported by the Spanish Government under Project MINECO-13-DPI2013-47176-C2-2-R and the Principality of Asturias under the grants "Severo Ochoa" BP14-140 and BP14-85 and by the Project FC-15GRUPIN14-143 and by European Regional Development Fund (ERDF) grants. 
converter, as stated in [20]. However, this topology requires four MOSFET, whereas the Dual Inductor Current-fed Push-Pull (DICPP) (see Fig. 1) proposed in [21], [22] achieves the same input current reduction with the use of only two MOSFET and only one transformer. The DICPP uses the same amount of switches when compared to the classic Current-fed Push-Pull (CPP) [22], and the transformer is a one winding to one winding which is simpler to design and build than the classic CPP transformer. This is particularly important to reduce the parasitic components that may cause an inadequate behaviour of the topology due to resonances in the output current or the losses in the passive snubbers that will decrease the efficiency of the single-stage.

Hence, this work proposes the optimization of the DICPP and enhances the scope of the topology in order to make it suitable for PFC with a simple control method. The operation in BCM makes the DICPP as a plausible solution for single-stage PFC in HB-LED drivers, which reduces the size of the EMI filter when compared to other topologies working in BCM and achieves high efficiency $(92 \%)$. However, it is not able to eliminate the classic bulk capacitor in PFC if a non-flicker behaviour needs to be guaranteed on the HB-LEDs. In that sense a high efficiency post-regulator stage can be used to remove the bulk capacitor and to individually control each HB-LED string $[\mathrm{X}]$.

This work is divided in several section: Section II, will analyze the proposed topology, as well as, discuss the most important features of the proposed driver with a dedicated subsection for the transformer and inductor design. Section III, will be dedicated to the most representative experimental results that were obtained with the proposed driver.

\section{WORKING PRINCIPLE}

\section{A. Static Analysis}

The concept of the HB-LED driver presented in this work (i.e. DICPP) is based on [21], where it was proposed as a dc-dc converter working in $\mathrm{CCM}$. Hence, this paper proposes to increase the scope of the topology to work as a PFC. The CPP converter is equivalent to a boost converter with galvanic isolation.

In order to achieve good quality rectification in the input current, a Loss Free Resistor (LFR) [23] behaviour is required. It is well known that a boost converter operating in BCM can achieve a LFR behaviour naturally. Therefore, the DICPP should also be able to achieve PFC naturally by working in BCM.

The operation of the HB-LED driver is summarized in Fig. 2 and 3 for BCM. Fig. 2 shows the three different stages that the topology undergoes during its operation, while Fig. 3 shows the most important waveforms to understand its operation. Fig. 2 (a) depicts the conduction from $\left[\mathrm{t}_{0}, \mathrm{t}_{1}\right]$ and $\left[\mathrm{t}_{2}, \mathrm{t}_{3}\right]$ when both switches are closed and the primary of the transformer is shortcircuited. Hence, both inductors are being magnetized by the input voltage ( $\left.v_{I N}\right)$. In Fig. $2(b)$, it can be seen the stage $\left[t_{1}, t_{2}\right]$ when $S_{1}$ is closed and $S_{2}$ is open, during this time $L_{I N 1}$ keeps getting magnetized whereas, $\mathrm{L}_{\mathrm{IN} 2}$ is demagnetizing and power is given to the load. The time interval from $t_{2}$ to $t_{3}$ is depicted by Fig. 2 (a) once again. Fig. 2 (c) shows the stage $\left[\mathrm{t}_{3}, \mathrm{t}_{4}\right]$ when $\mathrm{S}_{1}$
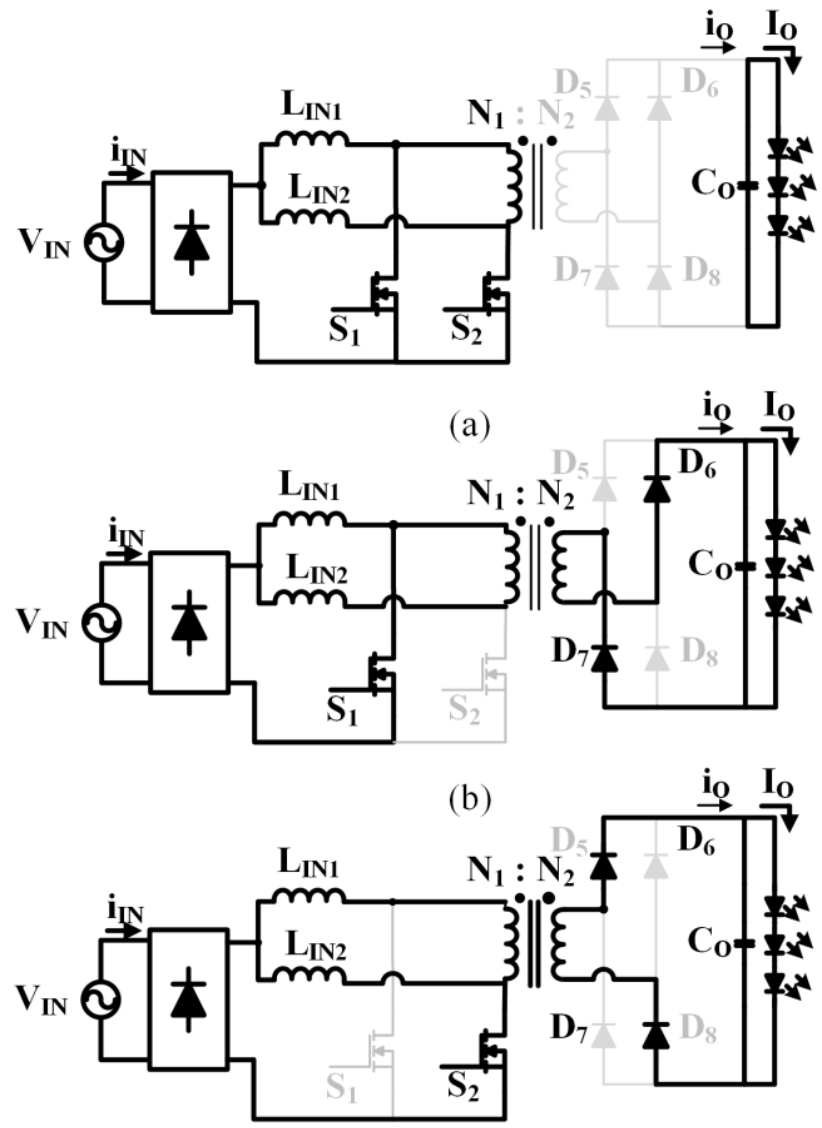

(c)

Fig. 2. Stages of the proposed single-stage HB-LED driver, DICPP. (a) $\left[\mathrm{t}_{0}\right.$, $\left.t_{1}\right]\left[t_{2}, t_{3}\right]$ Both switches are closed. (b) $\left[t_{1}, t_{2}\right] S_{1}$ is closed and $S_{2}$ is open. (c) $\left[t_{1}, t_{2}\right] S_{2}$ is closed and $S_{1}$ is open.

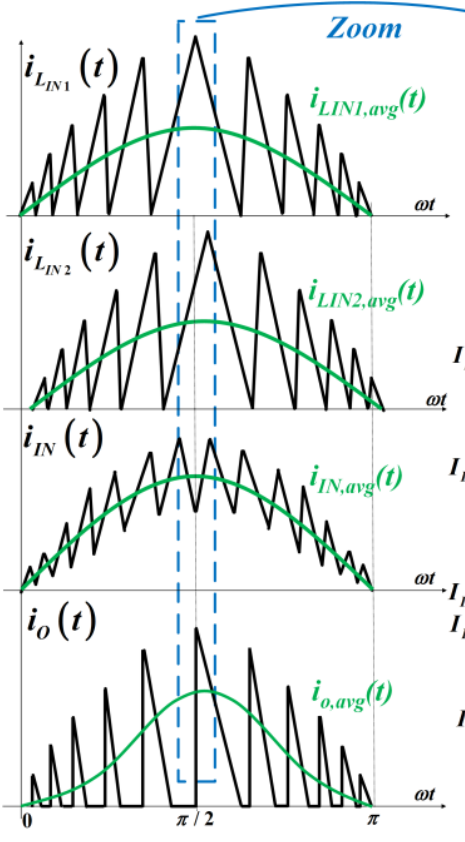

(a)

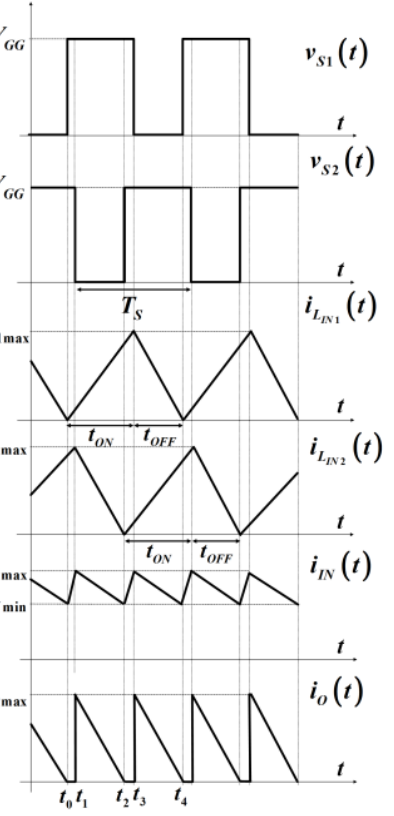

(b)
Fig. 3. Most representative waveforms of the topology. (a) Averaged at switching frequency. (b) Time domain waveforms. 
is open and $\mathrm{S}_{2}$ is closed, therefore magnetizing $\mathrm{L}_{\mathrm{IN} 2}$ and demagnetizing $\mathrm{L}_{\mathrm{IN} 1}$ while giving power to the load.

Fig. 3 (a) shows the input and output currents averaged at line frequency in green, whereas Fig. 3 (b) shows the time domain waveforms to analyze the topology in detail (i.e. at switching frequency). As can be seen in Fig. 3 (b), the time $\mathrm{L}_{\mathrm{IN}} 1$ is getting magnetized is equal to the on time of switch $S_{1}$ and the magnetizing time for $\mathrm{L}_{\mathrm{IN} 2}$ is equal to the on time of switch $\mathrm{S}_{2}$, being $\mathrm{L}_{\mathrm{IN} 1}$ magnetization, independent from the on time of $\mathrm{S}_{2}$ and $\mathrm{L}_{\mathrm{IN} 2}$ magnetization independent from the on time of $\mathrm{S} 1$. Therefore, the topology can be modelled as two independent boost converters interleaved with a 180 degrees phase-shift and galvanic isolation. This fact, will have an impact on the EMI input filter as has been reported in [26] for interleaved boost converters.

Hence, the control of the switches $\left(\mathrm{S}_{1}\right.$ and $\left.\mathrm{S}_{2}\right)$ is based on generating the control signal for $\mathrm{v}_{\mathrm{S} 1}$, and phase shifting this same signal 180 degrees to control $\mathrm{v}_{\mathrm{S} 2}$, by means of a Phased Locked Loop (PLL). It should be taken into account that the duty cycle (d) of this converter should always be higher than $50 \%$ due to the fact that when both switches $S_{1}$ and $S_{2}$ are open there is no demagnetizing path for $\mathrm{L}_{\mathrm{IN} 1}$ or $\mathrm{L}_{\mathrm{IN} 2}$, which could cause the switches destruction due to overvoltage. Hence, the need of a stage (Fig. 2 (a)), that overlaps both control signals.

By considering the stages from Fig. 2 and 3, the converter relationship between output voltage and input voltage in BCM can be obtained by means of studying the volt-second balance on one the inductors. Therefore, the converter gain can be defined by,

$$
m=\frac{v_{o}}{v_{g}(t)}=\frac{N_{2}}{N_{1}(1-d(t))},
$$

where $v_{0}$ is the output voltage, $v_{g}$ is the input voltage, $N_{2}$ and $\mathrm{N}_{1}$ are the turns number of the secondary winding and primary winding respectively.

From the previous analysis, it can be seen that in the DICPP each inductor works independently. $\mathrm{S}_{1}$ controls the magnetizing of $\mathrm{L}_{\mathrm{IN} 1}$ and $\mathrm{S}_{2}$ controls the magnetizing of $\mathrm{L}_{\mathrm{IN} 2}$. Therefore, it can be assumed that if both $\mathrm{L}_{\mathrm{IN} 1}$ and $\mathrm{L}_{\mathrm{IN} 2}$ are equal $(\mathrm{L})$, the variation of the inductor peak current ( $i_{\text {LIN1,peak }}$ and $\left.i_{\text {LIN2,peak }}\right)$ can be defined as,

$$
\begin{gathered}
i_{L_{I N 1}, \text { peak }}(t)=\frac{v_{g p}}{L} \sin (\omega t) t_{\text {on }}, \\
i_{L_{I N 2}, \text { peak }}(t)=\frac{v_{g p}}{L} \sin \left(\omega\left(t-\frac{T_{s}}{2}\right)\right) t_{\text {on }},
\end{gathered}
$$

by studying the voltage balance in the inductors during the stage $\left[t_{1}, t_{2}\right]$ for $L_{I N 1}$ and $\left[t_{3}, t_{4}\right]$ for $L_{I N 2}$. $v_{g p}$ is the peak value of the input voltage, $t_{\text {on }}$ is the on-time of each driving signal, which coincides with the magnetizing time of each inductor, $\omega$ is the angular frequency of the line voltage and $T_{S}$ is the switching period. If (2) and (3) are averaged in a switching period, equations (4) and (5) can be yield as,

$$
\begin{gathered}
i_{L_{I N 1}, a v g}(t)=\frac{v_{g p}}{2 L} \sin (\omega t) t_{\text {on }}, \\
i_{L_{I N 2}, a v g}(t)=\frac{v_{g p}}{2 L} \sin \left(\omega\left(t-\frac{T_{s}}{2}\right)\right) t_{\text {on }} .
\end{gathered}
$$

Therefore, branches ( $i_{\text {LIN1,avg }}$ and $i_{\text {LIN2,avg }}$ ) demand a sinusoidal current, in this case phase shifted $180^{\circ}$ from the point of view of the switching period $\left(\mathrm{T}_{\mathrm{s}}\right)$. Then, the input current demanded by the HB-LED driver is going to be sinusoidal, since it is the sum of the two sinusoidal waveforms, considering that the delay between them is negligible, as can be seen in Fig. 3 (a). Therefore, the average input current at switching frequency $\left(\mathrm{i}_{\mathrm{IN}, \mathrm{avg}}\right)$ can be expressed as,

$$
\begin{aligned}
& i_{I N, \text { avg }}(t)=i_{L_{I N 1, \text { avg }}}(t)+i_{L_{I N 2, \text { avg }}}(t)= \\
& =\frac{v_{g p}}{2 L} t_{o n} \sin (\omega t)+\frac{v_{g p}}{2 L} t_{o n} \sin \left(\omega\left(t-\frac{T_{s}}{2}\right)\right) \cong \\
& \cong \frac{v_{g p}}{L} t_{o n} \sin (\omega t) .
\end{aligned}
$$

For the correct operation in BCM, $t_{\text {on }}$ needs to be kept constant at a certain value that guarantees that the converter is going to demand a certain amount of power and the off-time of the driving signal $\left(\mathrm{t}_{\mathrm{off}}\right)$ is going to vary depending on the demagnetizing time of each the inductors until it reaches the zero current value. The zero current value is detected by a Zero Current Detection circuit (ZCD) based on a comparator. Considering that the average input current is going to be a sine wave, as stated in (6), by multiplying it to the input voltage then the input power can be defined by,

$$
p_{g}(t)=\frac{v_{g p}^{2}}{L} t_{o n} \sin ^{2}(\omega t)
$$

By averaging (7) a relationship between $t_{\text {on }}$ and well known design parameters can be made,

$$
t_{o n}=\frac{2 P_{G} L}{v_{g p}^{2}},
$$

where $\mathrm{P}_{\mathrm{G}}$ is the input power of the driver. Hence, by applying voltage balance on one of the inductors, (9) can be obtained as,

$$
\frac{v_{g p}}{L} t_{o n}=\frac{\frac{N_{1}}{N_{2}} v_{o}-v_{g}(t)}{L} t_{o f f}(t) .
$$

From this equation the variation of the switching period over time can be obtained and the switching frequency,

$$
\begin{array}{r}
T_{s}(t)=t_{o n}+t_{o f f}(t)= \\
=\frac{\frac{N_{1}}{N_{2}} v_{O}}{\frac{N_{1}}{N_{2}} v_{O}-v_{g p}|\sin (\omega t)|} t_{o n}, \\
f_{s}(t)=\frac{\frac{N_{1}}{N_{2}} v_{O}-v_{g p}|\sin (\omega t)|}{\frac{N_{1}}{N_{2}} v_{O}} \frac{1}{t_{o n}},
\end{array}
$$

From (11), the maximum and minimum frequency values can be obtained, which are of importance for the correct design of the topology and selection of the main switches. 


\section{B. Design Criteria of the HB-LED driver}

In order to design the HB-LED driver correctly some steps need to be followed.

First of all the transformer relation needs to be obtained from (1), considering $\mathrm{v}_{\mathrm{gp}}$ as the maximum value of the input voltage range (i.e. $\mathrm{V}_{\mathrm{gpmax}}$ ), $\mathrm{v}_{\mathrm{o}}$ as the output voltage at the full dimming value and $d_{\min }$ as the minimum duty cycle acceptable, which should be around 55\%.

After obtaining the transformer relation, the duty cycle needs to be calculated in nominal conditions, with that duty cycle and the desired switching frequency is possible to calculate the inductors required from (8). If the inductor value is feasible, (11) should be used to check if the frequency range is suitable. If not, then the inductance value needs to be adjusted to suit the designer specifications. Guaranteeing that the lowest frequency value is higher than $20 \mathrm{kHz}$ is a good practice to avoid any noise in the converter.

After having calculated all the previous parameters, the next step would be to select the main switches. For that reason is necessary to know the maximum current and voltage that they are going to endure, from (1) and (7),

$$
\begin{aligned}
& V_{\text {Smax }}=\frac{N_{1}}{N_{2}} v_{o}, \\
& I_{\text {Smax }}=\frac{P_{g}}{V_{\text {gpmin }}},
\end{aligned}
$$

where $\mathrm{V}_{\text {gpmin }}$ is the voltage peak of the minimum voltage in the range. As can be seen, the maximum voltage is completely reliant on the output voltage and the transformer relation. Considering that the transformer turns ratio is calculated based on the maximum input voltage, European/Universal range would require the use of switches with a higher breakdown voltage (i.e. $1200 \mathrm{~V}$ ).

For the sake of selecting the high frequency diodes (D5D8), the maximum values that need to be taken into account are shown,

$$
\begin{gathered}
V_{D \max }=V_{o}-\frac{N_{2}}{N_{1}} V_{\text {gpmin }}, \\
I_{D \max }=\frac{N_{1}}{N_{2}} I_{L_{I N 1}, \text { peak, } \max },
\end{gathered}
$$

where $\mathrm{I}_{\text {LIN1,peak,max }}$ is the maximum input current of the HBLED driver. As it can be seen, the breakdown voltage of the high frequency diode bridge can be low enough to guarantee the use of very low knee-voltage diode in order to improve the efficiency of the driver.

Finally, in order to be able to demagnetize both inductors in case of having the need to shut down the HB-LED driver, another winding is added to give a path for the demagnetization to occur, as has been done in previous works [16][17].

Even though, it is not shown in Fig. 2, the HB-LED driver also has a clamping snubber implemented to protect both switches from overvoltage.

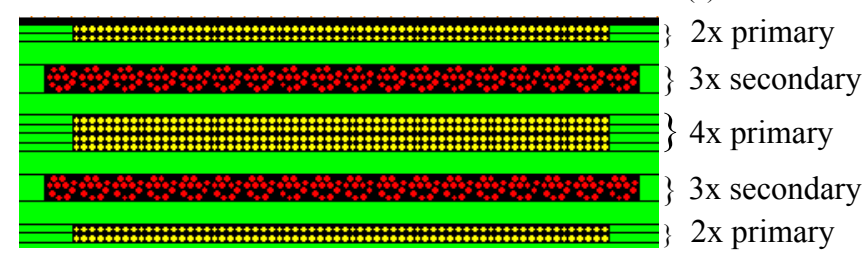

ॠम;

(b)

Fig. 4. Design of the implemented magnetics. (a) Transformer cross section. (b) Detail of the transformer secondary subwindings, each color represents a different subwinding in the same layer.

\section{Transformer design}

In push-pull converters, where the current through the primary transformer winding is abruptly changed whenever a transistor switches, leakage inductance should be as low as possible. Otherwise, each switching instant would cause a significant voltage spike, making the use of higher voltage rated transistors or protective devices such as snubbers.

Winding interleaving is a well-known procedure for reducing the leakage inductance. However, as a side effect of adding a high number of thinner sub-windings, a really low leakage inductance can only be obtained at the cost of a high parasitic capacitance. This proved to be troublesome, when voltage spikes due to leakage inductance were close to nonexistent but the transformer resonated due to stray capacitances similar to the transistor $\mathrm{C}_{\text {oss }}$. This recirculating currents not only increase the converter losses but also make the event detection for the control more difficult to implement, requiring complex filters.

This resonance has been studied in [27], where it is shown that both the leakage inductance and the stray capacitance play an important role. A low leakage inductance value is extremely important. A common target for a well-designed transformer is a leakage inductance at least thousand times lower than the transformer magnetizing inductance. The parasitic capacitor is nowhere as critical as a low leakage inductance. Nevertheless, it should be taken into account when designing the transformer.

Using planar magnetic technologies is a feasible option, whose main advantages are the ease of implementation of interleaved windings and the predictability and repeatability of the process [28]. However, in order to attain a low leakage inductance, a high amount of PCB layers are needed, rapidly increasing both its cost and the winding capacitance. Although some techniques have been presented in order to reduce parasitic capacitance in planar transformers [28] [29], for this paper a simpler, traditional transformer is designed.

Based on the previously shown design equations and specifications, an 11:1 transformer is designed aiming for low losses in a quite wide frequency range around $150 \mathrm{kHz}$. Its magnetizing inductance is not critical as long as it is much higher than $\mathrm{L}_{\mathrm{IN} 1}$ and $\mathrm{L}_{\mathrm{IN} 2}$. An EPCOS RM12 - N49 core is chosen for being compact and adequate to the design requirements. Several designs were simulated using ANSYS ${ }^{\circledR}$ Maxwell and PExprt.

As can be seen in Fig. 4 (a), the winding arrangement is kept rather simple in order to be able to easily assemble and replicate the transformer with regular manufacturing techniques and machinery. The primary winding consists of 8 different sub- 
TABLE I. TRANSFORMER PARASITICS FOR DIFFERENT IMPLEMENTATIONS

\begin{tabular}{|c|c|c|}
\hline & Stray Capacitance & Leakage inductance \\
\hline Target & $100 \mathrm{pF}$ & $21 \mu \mathrm{H}$ \\
\hline No interleaving & $10.99 \mathrm{pF}$ & $47.589 \mu \mathrm{H}$ \\
\hline Interleaving & $20.73 \mathrm{pF}$ & $5.498 \mu \mathrm{H}$ \\
\hline Foil-based & $58.36 \mathrm{pF}$ & $0.606 \mu \mathrm{H}$ \\
\hline Actual prototype & $45.80 \mathrm{pF}$ & $3.020 \mu \mathrm{H}$ \\
\hline
\end{tabular}

windings of 66 turns of AWG 35 copper wire, all connected in parallel.

The secondary winding consists of 6 different sub-windings of 6 turns. They are arranged in only two layers, interleaved with the primary, of three windings each. It is important to note, that each winding is built from Litz wire comprising 10 AWG 35 wires. This way, the total thickness is small enough to evenly spread the windings along the window height, thus reducing the leakage inductance even more. If a single, thicker winding was used on each layer, it would not fit the available winding area.

Different implementation options were also considered for the secondary winding. The use of copper foil is an interesting alternative, but the benefit does not justify the increase of the manufacturing difficulty, requiring custom foil thicknesses or even laser cutting for fitting the required turns in just one layer. Simulations did not show significant advantages over the preferred, simple designs, so this approach was discarded.

As the copper windings do not completely fill the winding area, PET insulating tape layers are added between them. This serves a dual purpose: fixing and insulating the primary and secondary layers and creating wider spaces between them, lowering the stray capacitance.

Table I shows the maximum target parasitic values for the desired transformer design, the values obtained for different implementations using Finite Element Analysis (FEA) simulations and the actual measurements from the implemented interleaved transformer. It can be seen that the not interleaved design does not comply with the desired specifications and the foil-based transformer provides a much lower leakage inductance at the cost of a highly increased assembly complexity. The interleaved transformer is easy enough to manufacture and fulfills the desired specifications.

The design of the input inductors is not as critical as that of the transformer, but a custom design is also used for this prototype. There is a wide range of commercial inductors which fulfill the inductance and frequency requirements with small form factors but high losses. An EPCOS RM8 - N97 core is chosen, with two AWG 29, 22-turn windings connected in parallel. The obtained design is only slightly bigger than equivalent commercial inductances but cut conduction losses by more than half.

\section{Control Strategies}

Figure 5 shows a diagram of the control loop of the HBLED driver. The current is sensed at the output of the high frequency diode bridge $\left(\mathrm{D}_{5}-\mathrm{D}_{8}\right)$ (io) with the help of a current transformer. The main reason for sensing $i_{O}$ is that it contains

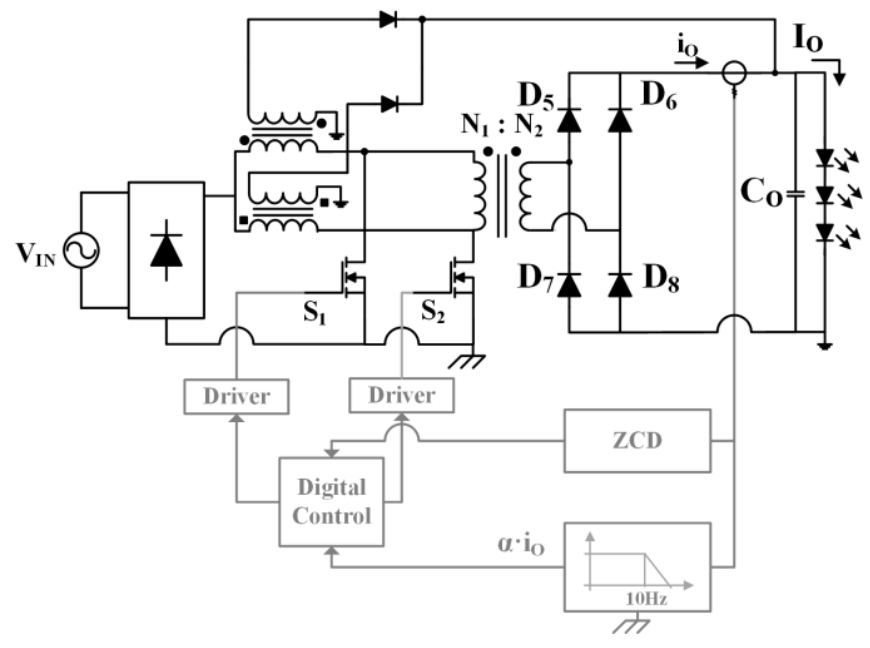

Fig. 5. DICPP with the output current closed loop.

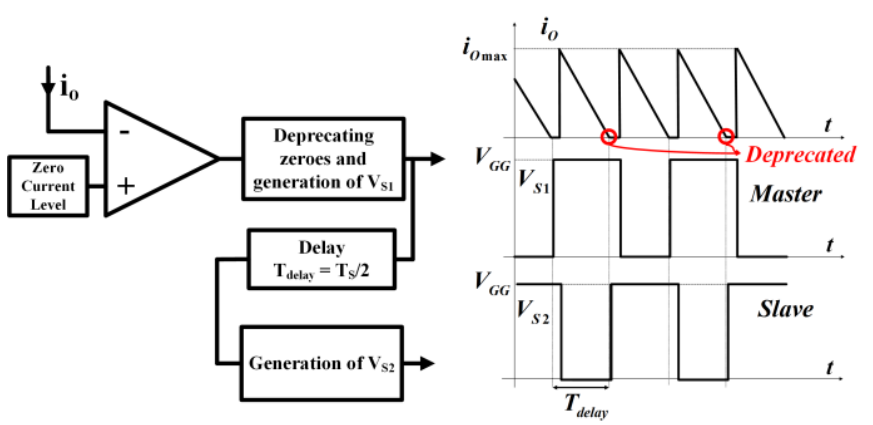

(a)

(b)

Fig. 6. Methodology for the zero current detection. (a) Basic control circuit. (b) Waveforms used in the zero detection.

the information from both inductor currents reaching the zero value and it also contains the information of the average output current value by applying a low pass filter to $\mathrm{i}_{\mathrm{O}}$ in order to obtain its average value. Meaning that from the same isolated measurement all the required information for the control is obtained.

By sensing io instead of the current in each inductor, as many interleaved boost PFC do, the control needs to be able to discern which switch to trigger. For that reason, the proposed control considers one zero and deprecates the other, meaning it generates the signal for $\mathrm{S}_{1}$ and from that signal by phase shifting 180 degrees taking into consideration the variable $\mathrm{T}_{\mathrm{s}}$ (see Fig. 6 (a)), it generates the signal to control the other switch, $S_{2}$ (see Fig. 6 (b)). This open loop interleaving method is similar to the ones proposed in literature based on master-slave techniques [30]. The master is selected at converter start-up, being able to be either $S_{1}$ or $S_{2}$. That switch will not leave the master status during the whole operation of the HB-LED driver. It is important to know that once a master is selected the next zero detection will be deprecated, as can be seen in Fig. 6 (b).

The output of the low pass filter is going to be the output average current $\left(\mathrm{I}_{\mathrm{O}}\right)$ scaled by a constant value $\alpha$, which will be compared with a reference inside the digital control, in order to regulate the output current of the driver. Moreover, there needs to be a variable to regulate, which in this case is $t_{\text {on, }}$, as well as, a transfer function that models the converter in order to design the 
TABLE II. COMPONENTS OF THE EXPERIMENTAL PROTOTYPE

\begin{tabular}{|c|c|}
\hline Fig. 1 reference & Value \\
\hline $\mathrm{D}_{1}-\mathrm{D}_{4}$ & $1 \mathrm{~N} 4007$ \\
\hline $\mathrm{D}_{5}-\mathrm{D}_{8}$ & FSV1060V \\
\hline $\mathrm{S}_{1}-\mathrm{S}_{2}$ & IPP65R225C7 \\
\hline FPGA & XC7A100T-1CSG324C \\
\hline $\mathrm{C}_{\mathrm{O}}$ & $60 \mathrm{~V}, 2.2 \mathrm{mF}$ Electrolytic Capacitor \\
\hline
\end{tabular}

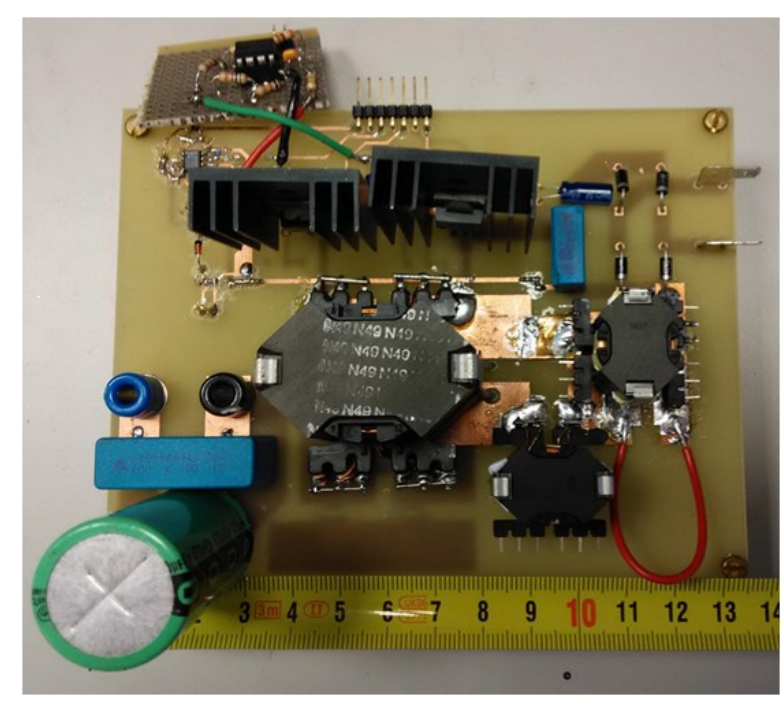

Fig. 8. Experimental prototype of the proposed DICPP.

regulator. In this case, $t_{\text {on }}$ will regulate the amount of power the driver demands. The small-signal analysis to obtain the transfer function of the converter is carried out similarly to that of an interleaved boost [31], by considering the HB-LEDs as a dynamic resistance $\left(R_{L E D}\right)$ in series with a voltage source $\left(V_{F}\right)$.

\section{EXPERIMENTAL RESULTS}

The HB-LED driver introduced in the previous sections has been designed for a maximum power of $100 \mathrm{~W}$, full range of the US single-phase line voltage and feeding five strings of $12 \mathrm{HB}-$ LED (W42180T2-SW) with their respective equalizing resistors, that are equivalent to $1.8 \mathrm{~A} / 48 \mathrm{~V}$ at full load. The switching frequency of the HB-LED driver varies from $55 \mathrm{kHz}$ at the lowest line voltage peak to $225 \mathrm{kHz}$ at the zeroes of the maximum line voltage. All the selected components for the HBLED driver have been summarized in Table II. It should be noted that the selected MOSFET for the test prototype had been $650 \mathrm{~V}$ superjunction MOSFET, since they need to withstand about $450 \mathrm{~V}$ in the full US range. As for the high frequency diode bridge, it is composed of $60 \mathrm{~V} / 10 \mathrm{~A}$ fast recovery silicon diodes with ultra-low forward voltage. In addition, the digital control of the whole HB-LED driver has been implemented in an FPGA for the simplicity and versatility that this platform offers. Nonetheless, an analog control can be also implemented. Fig. 8 shows a picture of the prototype that has been built to validate the analysis made in the previous sections.

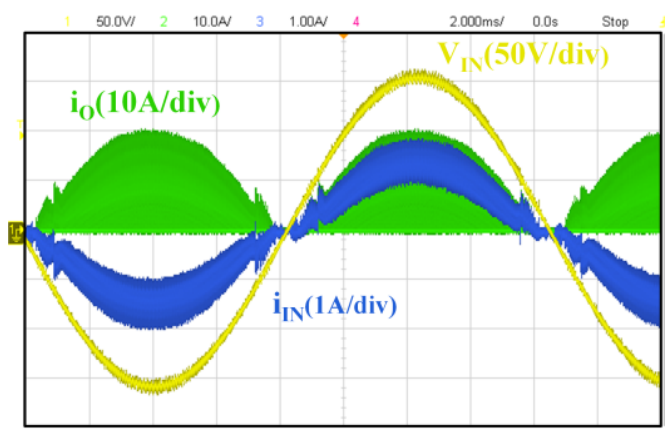

(a)

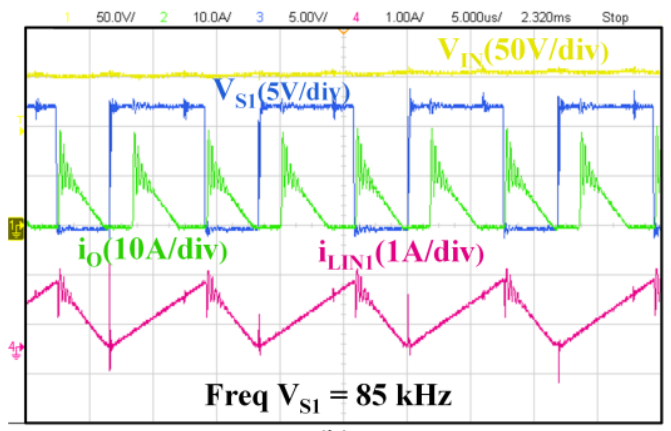

(b)

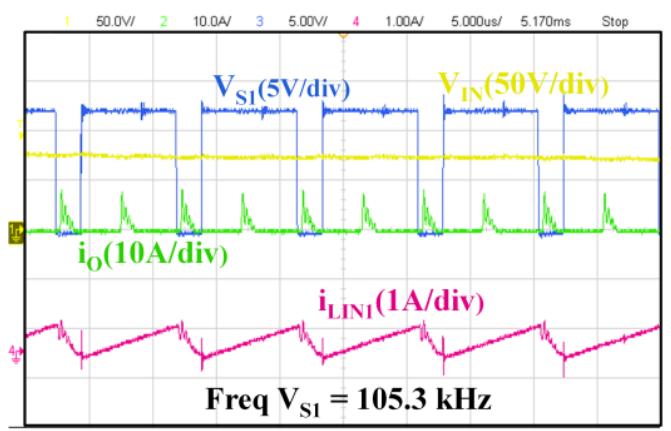

(c)

Fig. 9. Experimental input waveforms. (a) Input current and voltage, $i_{O}$ at 110 Vrms. (b) Zoom at the peak of the sine. (c) Zoom at $75 \mathrm{~V}$.

In Figure 9 (a), there is a snapshot of the oscilloscope for an input voltage of $110 \mathrm{Vrms} / 60 \mathrm{~Hz}$ and measured with no EMI filter to exemplify the low high frequency ripple of the input current. As it can be seen, the current follows the input voltage guaranteeing a LFR behaviour from the input and almost unity PF. Moreover, the input current presents low high frequency ripple considering that the HB-LED driver has its two inductors working in BCM. Therefore, interleaving of the two inductors can be deduced. Figure 9 (b) shows a zoom of Figure 9 (a), for the peak of the input voltage and Figure 9 (c) shows another point of the sinusoid, in this case at $75 \mathrm{~V}$. It can be observed, how $\mathrm{V}_{\mathrm{S} 1}$ triggers every two zeroes of $\mathrm{i}_{\mathrm{O}}$ and how the frequency of the control signal $\mathrm{V}_{\mathrm{S} 1}$ increases by moving to a lower voltage point in the input voltage sinusoid. The same is true for $\mathrm{V}_{\mathrm{S} 2}$ demonstrating the correct operation of the proposed control. $\mathrm{i}_{\text {LIN1 }}$ can also be seen in those graphs to illustrate that at least one of the inductors are operating in BCM as intended. The other inductor is working in $\mathrm{BCM}$ as well even though it is not shown in the graphs. 


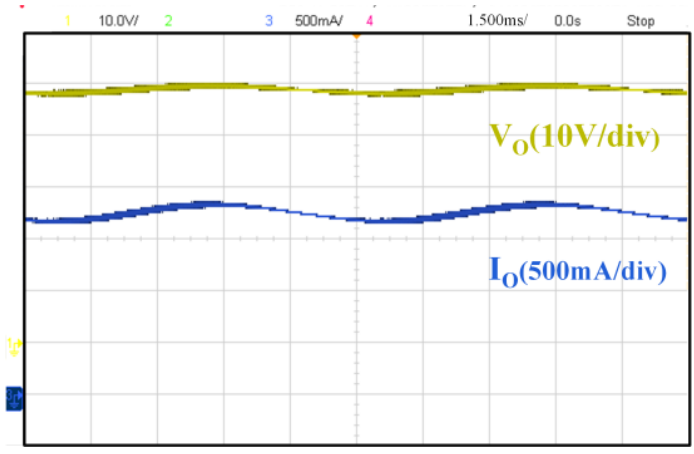

Fig. 10. Output voltage and current at full load.

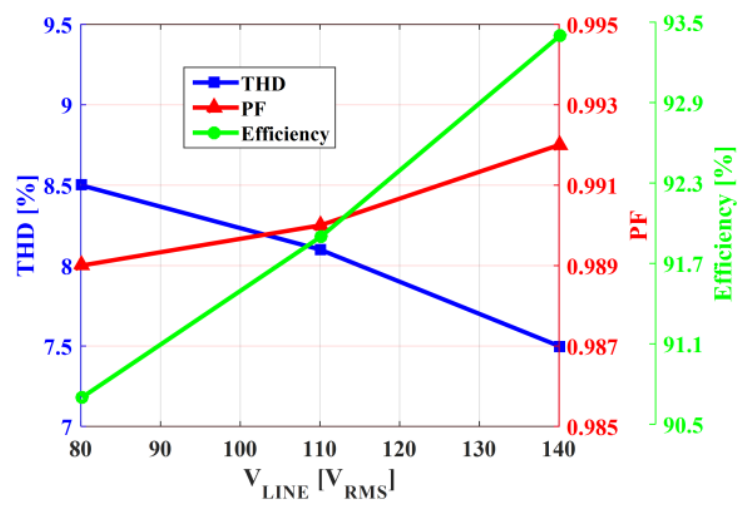

Fig. 11. THD, PF and efficiency vs. line voltage at full load.

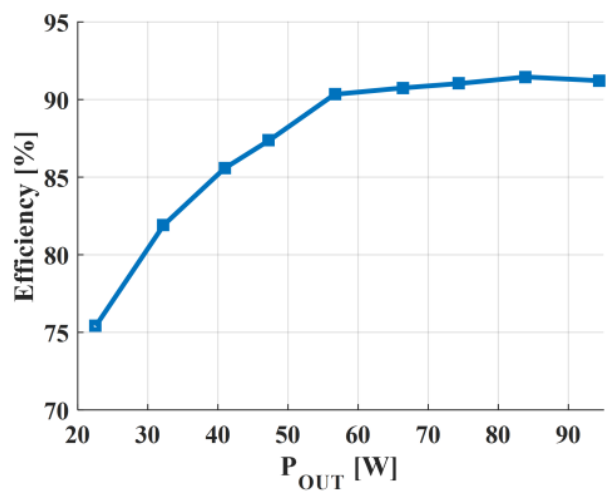

Fig. 12. THD, PF and efficiency vs. line voltage at full load.

Fig. 10, shows a snapshot of both the output voltage and current with the required electrolytic capacitor in order to reduce the output current ripple due to the well-known effect of the pulsating power in PFC.

In order to validate the HB-LED driver in nominal conditions, several waveforms under different conditions had been extracted from the oscilloscope as data and processed with MATLAB ${ }^{\circledR}$ to correctly analyze them. The parameters that are going to be extracted are: efficiency, THD, PF, compliance with Class C IEC 1000-3-2 [2-4].

The efficiency, THD and PF of the HB-LED driver are shown in Fig. 11 versus a variation of the line voltage. For the nominal conditions presented in Figure 9 (a), the efficiency is around $92 \%$, the THD is about $8 \%$ and the PF is 0.99 , which complies with the Energy Star ${ }^{\circledR}$ regulation [1]. It should be noted, that the efficiency does not go below $90 \%$ for the worst case scenario, at full load.

Fig. 12 shows the efficiency in dimming conditions for the nominal input voltage $\left(110 \mathrm{~V}_{\mathrm{rms}}\right)$. As can be seen, the efficiency of the HB-LED driver stays over $90 \%$ from full load to half load. However, at low output current the converter suffers an efficiency drop.

The input waveforms have also been used to extract the harmonics by using the Fourier series on them. Afterwards, these measurements are compared with Class C IEC 1000-3-2 harmonic limits. As can be seen in Fig. 13, the HB-LED driver complies with the regulation.

To limit the biological effects and detection of flicker in general illumination, the Modulation (\%) should be kept within the shaded region defined in [24], [25], where the Modulation( $\%$ ) calculation can be define as follows:

$$
\text { Modulation }(\%)=100 \cdot \frac{\left(L_{\max }-L_{\min }\right)}{\left(L_{\max }+L_{\min }\right)},
$$

where $\mathrm{L}_{\max }$ and $\mathrm{L}_{\min }$ correspond to the maximum and minimum luminance of each harmonic of the ac component of the output current, respectively.

The luminance of the HB-LEDs have been measured for the driver under study, being the waveforms for all the points under study extremely similar. After obtaining the luminance waveforms, all the harmonics have been obtained from $60 \mathrm{~Hz}$, which is the frequency of the fundamental harmonic, to $3 \mathrm{kHz}$ and compared with the graph proposed in the standard (see Fig. 14). As can be seen, all the harmonic content for both drivers falls within the shaded region, even the ones below $90 \mathrm{~Hz}$ which are the most crucial. Therefore, good light quality and nonharmful effects can be assured for the proposed HB-LED driver topology. The price to pay to achieve good light quality in this topology is the use of an electrolytic capacitor to reduce the output current ripple and therefore the luminance ripple.

\section{CONCLUSIONS}

A simple, single-stage, single-phase, isolated, high PF, HBLED driver with two switches referenced to the same ground has been reported and experimentally proven in this work. The HB-LED driver under study provides not only high PF and low THD, but it also provides a flicker free behaviour and high efficiency for a single-stage with galvanic isolation. In spite of, not being able to dispose of the traditional bulk capacitor in PFC. The proposed topology diminishes the size of the EMI filter by using the well-known interleaving method in BCM.

\section{REFERENCES}

[1] Revised ENERGY STAR Program Requirements for Solid-State Lighting Luminaires: Eligibility Criteria-Version 1.1, Dec. 2008

[2] Draft of the Proposed CLC Common Modification to IEC 61000-3-2 Document, 2006.

[3] Draft of the Proposed CLC Common Modification to IEC 61000-3-2/A2 Document, 2010.

[4] Electromagnetic Compatibility (EMC)-Part 3: Limits-Section 2: Limits for Harmonic Current Emissions (Equipment Input current $<16$ A per Phase), IEC1000-3-2, 1995. 


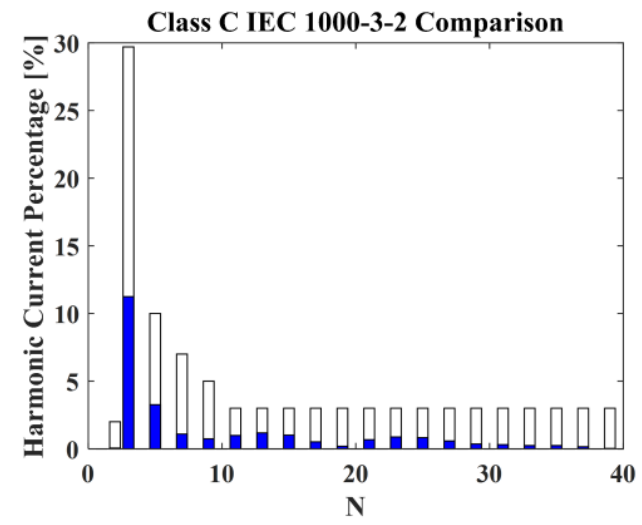

Fig. 13. Harmonic content of the input current for the topology under study and compliance with Class $\mathrm{C}$.

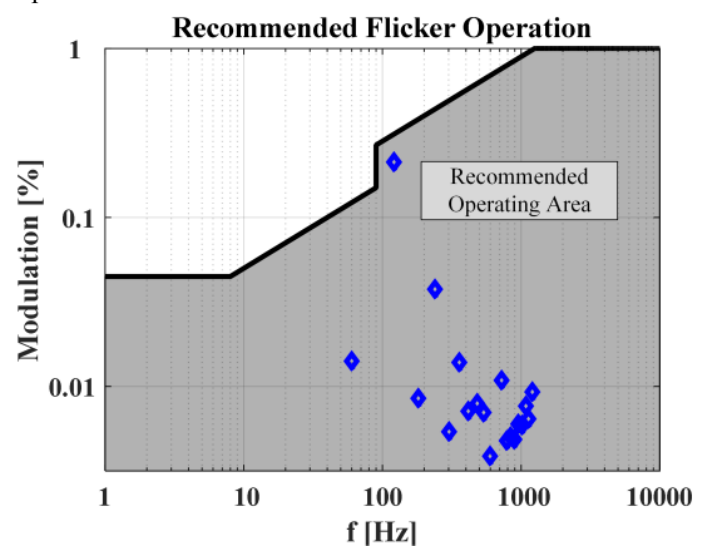

Fig. 14. Recommended flicker operation at full load for both drivers, P1789 [24]

[5] Xiaogao Xie; Zhou Lan; Chen Zhao, "A new primary side controlled high power factor single-stage flyback LED driver," in Energy Conversion Congress and Exposition (ECCE), 2012 IEEE , vol., no., pp.3575-3580, 15-20 Sept. 2012.

[6] Peng Fang; Yan Fei Liu, "Single stage primary side controlled offline flyback LED driver with ripple cancellation," in Applied Power Electronics Conference and Exposition (APEC), 2014 Twenty-Ninth Annual IEEE, vol., no., pp.3323-3328, 16-20 March 2014.

[7] Liang Jia; Yan-Fei Liu; Fang, D., "High power factor single stage flyback converter for dimmable LED driver," in Energy Conversion Congress and Exposition (ECCE), 2015 IEEE, vol., no., pp.3231-3238, 20-24 Sept. 2015.

[8] Hongbo Ma; Cong Zheng; Wensong Yu; Jih-Sheng Lai, "Bridgeless electrolytic capacitor-less valley fill AC/DC converter for twin-bus type LED lighting applications," in Future Energy Electronics Conference (IFEEC), 2013 1st International, vol., no., pp.304-310, 3-6 Nov. 2013.

[9] Yiwen Zhang; Ke Jin, "A single-stage electrolytic capacitor-less AC/DC LED driver," in Electronics and Application Conference and Exposition (PEAC), 2014 International, vol., no., pp.881-886, 5-8 Nov. 2014.

[10] Shu Wang; Xinbo Ruan; Kai Yao; Zhihong Ye, "A flicker-free electrolytic capacitor-less ac-dc LED driver," in Energy Conversion Congress and Exposition (ECCE), 2011 IEEE , vol., no., pp.2318-2325, 17-22 Sept. 2011.

[11] Yang Yang; Xinbo Ruan; Li Zhang; Jiexiu He; Zhihong Ye, "FeedForward Scheme for an Electrolytic Capacitor-Less AC/DC LED Driver to Reduce Output Current Ripple," in Power Electronics, IEEE Transactions on , vol.29, no.10, pp.5508-5517, Oct. 2014.

[12] Linlin Gu; Xinbo Ruan; Ming Xu; Kai Yao, "Means of Eliminating Electrolytic Capacitor in AC/DC Power Supplies for LED Lightings," in Power Electronics, IEEE Transactions on , vol.24, no.5, pp.1399-1408, May 2009.
[13] Lamar, D.G.; Sebastian, J.; Arias, M.; Fernandez, A., "On the Limit of the Output Capacitor Reduction in Power-Factor Correctors by Distorting the Line Input Current," in Power Electronics, IEEE Transactions on, vol.27, no.3, pp.1168-1176, March 2012.

[14] L. H. Dixon, "High power factor preregulators for off-line power supplies”, Unitrode Power Supply Design Seminar, 1988, pp. 6.1-6.16.

[15] Kocher, M.J.; Steigerwald, R.L., "An AC to DC converter with high quality input waveforms," in Power Electronics Specialists conference, 1982 IEEE, vol., no., pp.63-75, 14-17 June 1982

[16] Thottuvelil, V.J.; Wilson, T.G.; Owen, H.A., "Analysis and design of a push-pull current-fed converter," in Power Electronics Specialists Conference, 1981 IEEE, vol., no., pp.192-203, June 29 1981-July 31981.

[17] Yang, E.X.; Yimin Jiang; Hua, G.; Lee, F.C., "Isolated boost circuit for power factor correction," in Applied Power Electronics Conference and Exposition, 1993. APEC '93. Conference Proceedings 1993., Eighth Annual, vol., no., pp.196-203, 7-11 Mar 1993.

[18] Huber, L.; Irving, B.T.; Jovanovic, M.M., "Review and Stability Analysis of PLL-Based Interleaving Control of DCM/CCM Boundary Boost PFC Converters," in Power Electronics, IEEE Transactions on , vol.24, no.8, pp.1992-1999, Aug. 2009.

[19] Nha Quang Trong; Huang-Jen Chiu; Yu-Kang Lo; Chin-Yu Lin; Alam, M.M., "Modified current-fed full-bridge isolated power factor correction converter with low-voltage stress," in Power Electronics, IET, vol.7, no.4, pp.861-867, April 2014.

[20] Jun Wen; Taotao Jin; Smedley, K., "A new interleaved isolated boost converter for high power applications," in Applied Power Electronics Conference and Exposition, 2006. APEC '06. Twenty-First Annual IEEE , vol., no., pp.6 pp.-, 19-23 March 2006.

[21] Wolfs, P.J., "A current-sourced DC-DC converter derived via the duality principle from the half-bridge converter," in Industrial Electronics, IEEE Transactions on, vol.40, no.1, pp.139-144, Feb 1993.

[22] de Aragao Filho, W.C.P.; Barbi, I., "A comparison between two currentfed push-pull DC-DC converters-analysis, design and experimentation," in Telecommunications Energy Conference, 1996. INTELEC '96., 18th International, vol., no., pp.313-320, 6-10 Oct 1996.

[23] S. Singer, "The application of 'loss-free resistors' in power processing circuits," Power Electronics Specialists Conference, 1989. PESC '89 Record., 20th Annual IEEE, Milwaukee, WI, 1989, pp. 843-846 vol.2.

[24] IEEE Recommended Practices for Modulating Current in HighBrightness LEDs for Mitigating Health Risks to Viewers," in IEEE Std 1789-2015, vol., no., pp.1-80, June 52015.

[25] "RP-16-10, Nomenclature and Definitions for Illuminating Engineering", Illuminating Engineering Society.

[26] Z. Wang, S. Wang, P. Kong and F. C. Lee, "DM EMI Noise Prediction for Constant On-Time, Critical Mode Power Factor Correction Converters," in IEEE Transactions on Power Electronics, vol. 27, no. 7, pp. 3150-3157, July 2012.

[27] J. M. Kwon, E. H. Kim, B. H. Kwon and K. H. Nam, "High-Efficiency Fuel Cell Power Conditioning System With Input Current Ripple Reduction," in IEEE Transactions on Industrial Electronics, vol. 56, no. 3, pp. 826-834, March 2009.

[28] Z. Ouyang and M. A. E. Andersen, "Overview of Planar Magnetic Technology_Fundamental Properties," in IEEE Transactions on Power Electronics, vol. 29, no. 9, pp. 4888-4900, Sept. 2014.

[29] M. A. Saket, N. Shafiei, M. Ordonez, M. Craciun and C. Botting, "Low parasitics planar transformer for LLC resonant battery chargers," 2016 IEEE Applied Power Electronics Conference and Exposition (APEC), Long Beach, CA, 2016, pp. 854-858.

[30] L. Huber, B. T. Irving and M. M. Jovanovic, "Open-Loop Control Methods for Interleaved DCM/CCM Boundary Boost PFC Converters," in IEEE Transactions on Power Electronics, vol. 23, no. 4, pp. 1649-1657, July 2008.

[31] H. Y. Kanaan, A. Marquis and K. Al-Haddad, "Small-signal modeling and linear control of a dual boost power factor correction circuit," Power Electronics Specialists Conference, 2004. PESC 04. 2004 IEEE 35th Annual, 2004, pp. 3127-3133. 